\title{
Revista

\section{Poéticas e políticas para criação de memórias culturais em ambientes programáveis}

\section{Cibercultura}

\section{Poetics and politics to create cultural memories in programmable environments}

\section{Carlos Henrique Rezende FalCl}

Doutor em Literatura pela Universidade Federal de Santa Catarina. Professor do Programa de Pós-Graduação em Comunicação Social da Universidade Federal de Minas Gerais - UFMG.

<chfalci@gmail.com>

\section{LUCIANA ANDRADE GOMES}

Mestre em Literatura pela Universidade Federal de Minas Geraiss - UFMG

<lucianadrade@gmail.com>

\section{RESUMO}

O propósito deste texto é investigar as questões poéticas e políticas envolvidas na criação de objetos de memória em ambientes programáveis. Discute-se a relação entre memórias comunicativas e culturais e o modo como elas são produzidas nas redes sociotécnicas. Nesses ambientes, em função da forma como eles permitem agregações e combinações, o político se mostra como algo manipulável, aberto, que pode ser retorcido e subvertido. É na falta de compromisso com o factual e na abertura para o imaginário que surge o cruzamento entre o político e o poético. A criação poética é entendida a partir do uso de metadados e do comportamento

\section{ABSTRACT}

The purpose of this paper is to investigate the poetic and political issues involved in creation of memory objects in programmable environments. We discuss the relationship between communicative and cultural memories and how they are produced in socio-technical networks. In such, environments due to the way they allow aggregations and combinations, the politician shows up as something manipulative, open, which it can be subverted. It is in the lack of commitment to the factual and in the opening for the imaginary that arise the intersection between the political and the poetic. The poetic creation is understood from the use of 
dos ambientes programáveis. Eles realizariam a passagem entre memória comunicativa e cultural e entre o político e o poético.

Palavras-chave: Memórias comunicativas. Memórias culturais. Ambientes programáveis. metadata and the behavior of programmable environments. They would make the transition between communicative and cultural memory and between the political and poetic.

Keywords: Communicative memories. Cultural memories. Programmable environments.

\section{Nos rastros da experiência}

B runo Latour, em "Reagregando o social" (2012), afirma que toda ação gera um D rastro de caráter polissêmico e potencialmente recuperável. E essa produção de rastros necessita da intervenção de um ator em constante movimento para garantir sua existência. Nesse sentido, uma das possibilidades é pensar a memória como algo em constante devir. Segundo Hoskins, em "The digital distribution of memory" (2009), o processamento de dados em ambientes programáveis produz uma simulação de memórias que são recriadas indefinidamente. Isso porque a temporalidade de um evento, nos ambientes digitais, pode ser trabalhada de maneira contínua e emergente, e não pontual como no caso de muitos registros realizados em mídias tradicionais. Se o tempo relativo a um evento se distende em várias direções e os rastros produzidos podem ser resgatados a qualquer momento, a sua memória simulada seria aquela em estado de potência, em vias de metamorfose. A memória se modifica e se atualiza pela enorme capacidade de expressão pessoal oferecida pelas mídias digitais, bem como pela criação e compartilhamento dos relatos, possibilitados pelo modo de existência das redes sociotécnicas.

Entretanto, apesar de problematizar o acúmulo de conteúdos, Hoskins ainda mantém a visão tradicional de uma memória única, que busca o resgate de um 
acontecimento passado da forma como ele teria acontecido. Essa visão ainda nos parece refém de uma percepção que desconsidera que um arquivo é um registro, mas também é produtor do próprio evento que registra. Nos ambientes programáveis, parece haver uma intensificação da importância poética dos modos de registro na criação de memórias culturais. Como discutiremos mais adiante, há projetos em que o aparecimento de um objeto de memória se faz justamente em função do modo como a lógica de programação agrupa conteúdos dispersos na rede.

Por outro lado, o foco nos relatos pessoais parece extremamente relevante para pensarmos o fluxo de associações entre os atores em movimento. Van Dijck, em "Mediated memories in the digital age" (2007), apesar de não romper completamente com a ideia de um passado latente, trabalha com a noção de memória mediada, dando ênfase aos registros de caráter marcadamente individual. A autora define esse tipo de memória como um produto das atividades humanas que são mediadas pelos dispositivos midiáticos, tornando-se uma memória cultural pessoal. Ela propõe uma visão cultural da memória baseada na criação dos relatos, no fortalecimento da subjetividade e na emergência dos conflitos entre público e privado; individual e coletivo.

Van Dijck menciona uma pesquisa realizada com a seguinte prerrogativa: "que objetos você tentaria salvar se houvesse um incêndio em sua casa?" (Van Dijck, 2007, p. 35). E foram justamente os objetos pessoais, com forte carga simbólica, como os álbuns de fotografia, que motivaram as respostas de grande parte dos entrevistados. Isso confirma que os traços de pessoalidade e permanência estão realmente impressos na noção de memória. Para a autora, as memórias são "instrumentos e objetos de inscrição e de comunicação: dispositivos pelos quais os seres humanos procuram estabelecer sua própria identidade" (Van Dijck, 2007, p. 39). 
Pensando nisso, uma primeira questão política surge, então, como resultado de um aparente embate entre a noção de uma memória que resgataria o passado, e uma memória que se atualiza e funciona como constante devir. E nos parece que essa questão também se associa aos conflitos entre público e privado; e entre uma memória marcadamente cultural e uma memória mais volátil, produzida de maneira não hierarquizada.

\section{Entre memória cultural e memória comunicativa}

Jan Assman, em "Collective memory and cultural identity" (1995), define a memória cultural como todo conhecimento obtido por meio de práticas sociais repetidas ao longo do tempo, que funcionam como elementos que estruturam o comportamento e a experiência de vida de um grupo social. A memória cultural seria construída pela cristalização de ritos, eventos, acontecimentos, os quais poderiam ter seus significados transmitidos através do tempo. Já a memória comunicativa seria baseada na comunicação cotidiana: caracterizada por um alto grau de não especialização, instabilidade temática e desorganização. Na visão do autor, ela seria demasiadamente instável para se configurar como uma cultura objetivada, e logo, como elemento capaz de identificar uma coletividade.

A memória cultural, para existir, solicitaria algum tipo de ordenamento e fixação temporal, o que comumente acontece quando essa memória se encontra registrada em suportes físicos, como a escrita em papel, a fotografia, as imagens em movimento etc. Os suportes físicos de registro da memória cultural pareceriam ser capazes de minimizar a velocidade de mutação das memórias coletivas, ao se dissociarem, aparentemente, da dinâmica do corpo social em que tais memórias foram produzidas. Essa premissa se mostra perigosa, uma vez que se baseia numa lógica tecnológica 
determinista e rígida, em que os objetos técnicos não seriam nada além de repositórios inertes dos acontecimentos.

Entretanto, não nos parece que os ambientes programáveis, ou mesmo os objetos técnicos, sejam simplesmente bancos de informações que não interferem naquilo que se informa. A visão de arquivo desenvolvida por Derrida em "O mal de arquivo" (2001) é fundamental para uma visão das políticas envolvidas na criação de memórias em ambientes programáveis. Entre as várias questões indicadas no texto de Derrida, a primeira que destacamos é a afirmação feita pelo autor de que o arquivo não pode existir sem o espaço instituído de um lugar de impressão. Ora, os ambientes programáveis são, ao mesmo tempo, lugares de impressão e espaços capazes de se tornarem instituídos. Ousaríamos dizer que os arquivos aqui, não são somente os conteúdos que surgem nesses ambientes, mas o seu próprio modo de funcionamento. Não se trata de enunciar um novo tipo de arquivo, mas de discutir em que medida as formas programáveis radicalizam propostas políticas já presentes em outros objetos técnicos.

Leroi-Gourhan, em "O gesto e a palavra" (1990), afirma que, com o surgimento dos textos impressos, os leitores se depararam não só com um enorme conjunto de memória coletiva, bem como foram confrontados com a impossibilidade de fixar completamente essa memória, uma vez que os suportes escritos permitiram a multiplicação incessante do registro dos fatos e acontecimentos de sua época. Por outro lado, Featherstone, em "Archiving cultures" (2000), argumenta que os suportes de memória transformam não somente o modo de produção dessas memórias, mas as próprias condições que definem o que se denomina cultura e como os grupos sociais compartilham essa cultura. Na mesma linha, Brockmeier, em "Remembering and forgetting"(2002), indica uma mobilidade maior da memória cultural, visto que esse tipo de memória está diretamente associado aos contextos discursivos que a produzem. 
Van Dijck fala do potencial contínuo de autoformação da memória, pois podemos alterar ou até apagar algum registro. Isso significa que as memórias são "reescritas" sempre que ativadas, o que configura uma nova forma de experiência, voltada para o compartilhamento do pessoal a partir dos agenciamentos coletivos. Assim, a memória incorpora uma dimensão criativa e menos factual. Ela surge como um conceito relacional, sujeito às modificações que afetam as instâncias narrativas nas quais ela se manifesta.

Em projetos como We feel fine (http://wefeelfine.org) as relações estabelecidas entre as "lembranças" visualizadas são instituídas pela forma como o ambiente funciona. $\mathrm{O}$ site permite a visualização de frases escritas em milhares de blogs, que são rastreadas a partir de um conjunto de regras executadas por um código específico. Os blogs onde é feita a pesquisa derivam de várias fontes, entre elas LiveJournal, MSNSpaces, MySpace, Blogger, Flicker etc. O programa deve buscar, de dez em dez minutos, frases que contenham a sequência "I fell" ou "I am feeling". Uma vez que ele encontra frases com essa sequência, elas são separadas e o programa faz uma nova busca, comparando as palavras dentro da frase com um banco de dados com cinco mil palavras que expressariam sentimentos. Ao encontrar, na frase que foi separada, uma palavra que se encontra no banco de dados, o programa cria uma visualização na interface do projeto, que consiste em uma esfera colorida que se move pela tela. A cor da esfera corresponde ao tipo de sentimento expresso pelo adjetivo encontrado.

A memória criada nessa interface é um arquivo, tomando a noção desenvolvida por Derrida, que se comporta tanto como instituidor quanto conservador. O programa institui um modo de agregar informações dispersas e produzidas com fins muito distintos entre si, e conserva essas informações no modo como a interface se apresenta. Mas como a busca é feita incessantemente e os posts nos blogs não param de serem escritos, a memória que a interface cria está sempre prestes a desaparecer. A própria lógica de instituição presente nesse tipo de arquivo já indica que ele só conserva o 
que é feito como registro temporário, registro cada vez mais momentâneo de um acontecido.

Aqui, nos parece já ser possível falar de uma política do arquivo, nos ambientes programáveis, que é também uma poética da memória em ambientes programáveis. A norma instituinte do grande arquivo, que é a interface de We feel fine, é o procedimento poético que faz a interface surgir. Cabe ressaltar ainda que a forma de busca do programa também permite delimitar memórias específicas, de acordo com informações como gênero (masculino, feminino - são as únicas duas opções do programa), idade, tipo de sentimento, estado, data do post e condição meteorológica no momento em que o post foi criado. Esses dados são coletados do perfil da pessoa que possui o blog. Novamente, a política do programa revela-se como procedimento poético, porque produz a experiência de memória que chega ao interagente. A abordagem do projeto aproximaria a memória cultural da memória comunicativa, uma vez que cada post, em si, não é produzido de maneira centralizada, de forma a perpetuar uma lembrança coletiva, perene.

No entanto, a natureza dessa memória cultural deve ser pensada de modo distinto em relação ao conceito de Assman (1995), ao menos em parte. A ordenação da interface ganha um componente de eventualidade próprio das maneiras de visualização da interface. O conteúdo aparece então como um acontecimento de memória, e evoca a si mesmo como rastro de outra memória talvez mais permanente, aquela relacionada à lógica de programação. Não há, entretanto, uma durabilidade definida dessa memória, uma vez que ela é um agregado de experiências, um rastro do funcionamento dos programas que estruturam We feel fine.

\section{Poética, memória e individuação técnica}

Uma das maneiras de realizar a passagem entre poética e memória, nos ambientes programáveis, é percorrer os caminhos da individuação técnica, caracterizada por 
Neves (2006) quando fala do apelo do objeto técnico. Nesse caso, a individuação técnica produz a singularidade no seio dos objetos técnicos, ela os provoca a funcionarem de maneira a revelar o que os individua, e isso permite percebê-los então como capazes de agenciamentos. A singularidade

consiste no facto (sic) de a matéria inerte, ainda que organizada no objeto técnico, evoluir ela própria na sua organização: portanto, já não se trata simplesmente de uma matéria inerte nem tão-pouco de uma matéria viva. É uma matéria inorgânica organizada que se transforma com o tempo tal como a matéria viva se transforma na sua interação com o meio."

(Neves, 2006, p. 73)

Os ambientes programáveis são tomados neste artigo enquanto capazes de individuação técnica, capazes de serem e criarem atos individuantes. Um processo individuante é um ato poético porque faz com que o próprio comportamento do objeto técnico revele sua capacidade de agenciamento presente na transdução que ele realiza entre estados distintos de informação. Numa analogia com o comportamento dos ambientes programáveis, a individuação é o momento de manifestação da imagemmatriz, em que é possível perceber o funcionamento das operações computacionais que irão preencher a memória da imagem (Couchot, 2003). É a imagem-matriz que abre o caminho para encontrarmos o espaço utópico e o tempo ucrônico, componentes centrais também da poética dos ambientes programáveis. Eles são o resultado de processamentos de códigos, de cálculos computacionais que engendram um espaço híbrido, que adere ao real e o faz vibrar, um espaço que resulta de processos de 
transdução entre o orgânico e o não-orgânico; nesse instante se manifesta a relação transindividual, como nos diz Pinheiro Neves. O humano aqui pode se revelar intimamente conectado com a técnica e com um biológico não-humano.

A individuação técnica, ao produzir a singularidade do ambiente programável, mostra também a memória em construção presente nesse movimento. Essa memória surge como uma intensidade do comportamento da imagem-matriz. Ela é o ato individuante, uma ação que abre os processos computacionais à manipulação, no seu sentido mais amplo, os abre ao toque, à sensação de sua materialidade, feita de cálculo e de códigos de programação em constante ativação. Acessa-se o fenômeno da individuação, que não pode ser reduzido às coisas individuais em si.

A poética da memória nos ambientes programáveis é fortemente preenchida pelo tempo ucrônico, tempo aberto, de síntese, dos múltiplos cálculos que o produzem. Não há aqui um tempo cronológico ligado ao tempo real, o tempo ucrônico é um tempo que se auto-engendra a partir da individuação que o ambiente programável provoca e ao qual ele mesmo está sujeito. Ela é a individuação, o ato de individuar em funcionamento, e é também o conjunto de rastros digitais que percebemos nas manifestações que a imagem-matriz cria. Tais manifestações se situam na fronteira entre o aparecimento e o evanescimento, pois é de sua natureza serem um elemento em movimento, um estado de cálculo do programa. Quando o processo individuante é tocado, vibra com um novo estado de todo o conjunto que o produz, há uma mudança no programa, em função da nova informação, e outra singularidade é produzida. Surge, então, uma nova imagem-matriz, cuja permanência é uma função da capacidade do ambiente de se manter em constante estado de ser programável. A programabilidade dos ambientes assim denominados encontra-se vinculada, nas obras que analisamos, aos modos de funcionamento das redes, à lógica do compartilhamento, associada também aos metadados. 
Dessa forma, o surgimento de uma lógica comunicacional calcada na ideia de compartilhamento tornou-se fundamental para compreendermos as formas de agenciamento entre os atores e os rastros deixados por essas associações a partir da imagem-matriz. Latour, em sua teoria ator-rede, abarca a materialidade da comunicação, levando em conta os diversos híbridos formados por humanos e não humanos, que surgem nos processos de individuação. Ele reconhece essas instâncias como atores na produção da experiência. Os atores, então, correspondem a toda figura potencialmente capaz de agir e deixar rastros, incluindo pessoas e objetos materiais. Eles podem ser caracterizados como tudo aquilo que afeta um estado de coisas. O grande lema da TAR é seguir os próprios atores, "ou seja, tentar entender suas inovações frequentemente bizarras, a fim de descobrir o que a existência coletiva se tornou em suas mãos" (Latour, 2012, p. 31).

Além disso, com a teoria ator-rede, o "social" passa a ser entendido como um movimento peculiar de reassociação e reagregação. Isso porque, na acepção tradicional do termo, o "social" "significa aquilo que já está reagregado e age como um todo, sem insistir muito na natureza do que foi reunido, amarrado e empacotado conjuntamente" (Latour, 2012, p. 71). Porém, na visão do autor, é impossível afirmar que um vínculo é durável, pois o "social" [...] "só relampeja brevemente no momento fugaz em que novas associações estão reunindo o coletivo juntas" (Latour, 2012, p. 229). E, nesse caso, o coletivo substitui a ideia de "sociedade", tornando-se uma ação que arregimenta diversos tipos de forças heterogêneas (Latour, 2012, p. 112).

Assim, se não existe uma sociedade instituída, significa que as associações só acontecem nas oscilações. E a rede é justamente o resultado dos traços deixados por um agente em movimento. Ou seja, quando falamos em rede, falamos em mobilidade. Latour enfatiza que a força de inércia não se aplica no caso do "social", pois esse é dotado de um potencial performativo que desaparece quando não é mais representado. 
Nesse caso, o autor define os meios para produzir o "social" como mediadores que "transformam, traduzem, distorcem e modificam o significado ou os elementos que supostamente veiculam” (Latour, 2012, p. 65).

\section{A experiência compartilhada nos coletivos sociotécnicos}

Como já indicado, para Assman (1995) a memória comunicativa tem um teor de instabilidade que a incapacitaria para se configurar como uma cultura objetivada, e logo, como elemento capaz de identificar uma coletividade. Além disso, a principal limitação da memória comunicativa na estruturação da identidade de um grupo social seria seu horizonte temporal limitado, uma vez que o horizonte da memória comunicativa se modifica diretamente com o passar do tempo. É interessante notar, entretanto, que a institucionalização que caracteriza a memória cultural tem suas bases remontadas ao dia-a-dia, embora ela se distancie da mudança diária constante em função da sua lógica de objetivação cultural.

Uma das questões relacionadas à poética e política da memória em ambientes programáveis diz respeito, justamente, ao fato de que a eventualidade não nos parece ser um problema para a criação da memória, mas sim um componente central das interfaces digitais. E o uso de metadados pode fortalecer a conexão e o cruzamento entre memórias culturais e memórias comunicativas. Afinal, aplicar um conjunto específico de metadados a um grupo heterogêneo de informações pode revelar ligações mais fortes entre tais dados, e que não foram exploradas porque os dados foram capturados de maneiras e em momentos muito diversificados. Se as formas variadas de registro apresentam o perigo de enfraquecer a memória episódica, potencialmente elas também trazem consigo outra forma de encarar as memórias mediadas tecnicamente.

Os metadados são vistos como linguagem, como um conjunto de normas e procedimentos que traduzem informações específicas, vindas de outro meio, em um 
conjunto codificado de informações. Essa linguagem está, portanto, sujeita igualmente às transformações que o uso do código pode produzir no seu seio. Comportam-se, assim, os metadados, como objetos técnicos, principalmente quando realizam alguma forma de individuação. Nesse sentido, os metadados tornam-se potentes para gerar atualizações da memória externa que ajudam a organizar e criar. Articulam-se assim as informações que um determinado sistema é capaz de capturar, num processo simultâneo de "epigênese, articulada com uma morfogênese incorporada no corpo" (Neves, 2006, p. 71). Essa morfogênese também afetará o próprio corpo do ambiente programável, que é derivado da relação entre o humano e a técnica. Encontra-se aqui a capacidade poética dos metadados para fazer vibrar a memória em ambientes programáveis.

Essa discussão se torna visível no projeto This is Now (http://now.jit.su/), uma plataforma criada pelos brasileiros Marcio Puga e Maurício Massaia, e pelo sueco Per Thoressonque, que usa o Instagram para compor um mosaico de imagens de doze cidades do mundo (no Brasil, apenas São Paulo e Rio de Janeiro). Seu funcionamento é automático, captando e arquivando as imagens por meio do rastreamento das geotags ("etiquetas" que visam descrever a geolocalização do objeto). Assim que as imagens são carregadas pelo aplicativo, imediatamente elas vão para a página do projeto. Além das classificações das cidades, existe um espaço destinado às imagens intituladas como "em torno do mundo", em que não são especificadas as geolocalizações.

A página possui uma interface simples e funcional. As cidades estão divididas categoricamente e exibem as datas e os horários locais de cada uma. Basta selecionar a opção de sua preferência para visualizar um mosaico repleto de imagens diversas e aleatórias que são apresentadas da esquerda para a direita. O fluxo depende do volume de imagens produzidas e compartilhadas naquele momento (Fig. 1). 


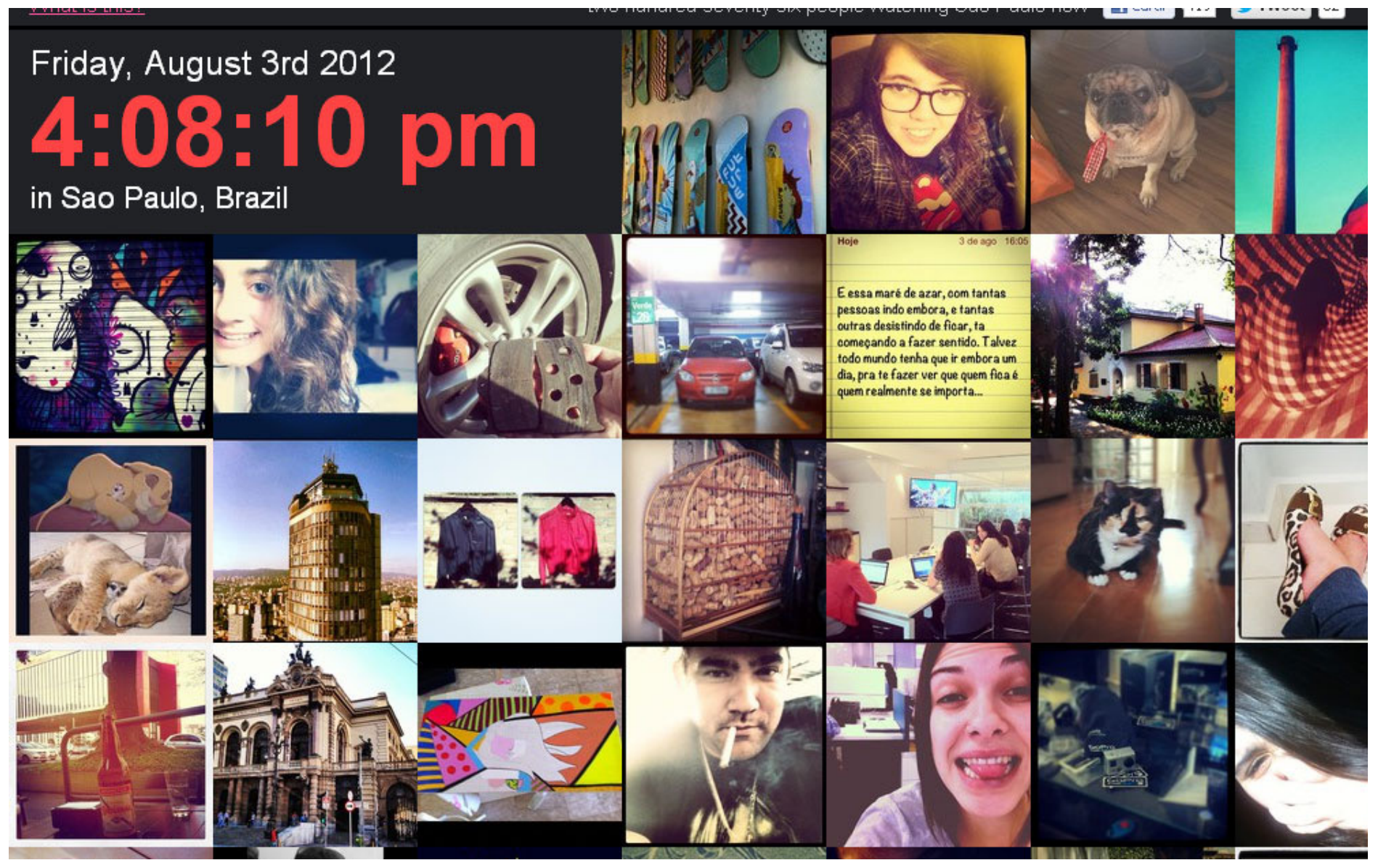

Figura 1 - Imagens com a geotag da cidade de São Paulo no This is Now. 
Também é possível saber quantas pessoas estão visualizando a página da cidade ao mesmo tempo em que você, acompanhando a contagem dos usuários online no canto superior direito da tela. Outro recurso interessante é a conexão com as plataformas sociotécnicas, contando quantas vezes a página foi "curtida" pelos usuários do Facebook e quantas "tuitadas" ela recebeu dos usuários do Twitter.

A partir do uso dos sistemas de geolocalização, a plataforma engendra espaços híbridos de circulação de sentido. O uso das geotags aumenta o potencial comunicacional e de monitoramento dos rastros deixados pelos atores, inclusive pelos próprios lugares. Essa forma de classificação transforma a experiência cotidiana em uma série de dados que vão circular pelos ambientes programáveis e absorver a lógica do banco de dados. No entanto, a própria interface possui capacidade afetiva, visto que também se torna um agente transformador, o que sinaliza que esses dados estão em permanente modificação, em permanente estado de construção de relatos. Apesar dos processos de indexação, o que circulam são formas fragmentadas de subjetividade. Dessa maneira, na visão de Lucia Santaella e Renata Lemos em Redes sociais digitais, "pensar, agir, sentir não dispensam hoje a ecologia cognitiva e afetiva que brota dos fluxos nas redes ubíquas de comunicação" (Santaella; Lemos, 2010, p. 53).

A intimidade torna-se, então, matéria-prima para a construção de narrativas na rede, uma estratégia de estetização da experiência. Segundo Paula Sibilia, em "O show do eu" (2008), é possível falar de uma inversão na ordem da visibilidade. A autora mostra a passagem de um "eu" romantizado pelas narrativas pessoais introdirigidas, pontuando a existência dos diários secretos, para uma intimidade que se apresenta como forma de existência midiática. Para ela, isso se deve ao acesso às novas tecnologias móveis que permitem uma "autoestilização imagética", ou seja, já estamos mediados pela ideia de mobilidade. Nesse contexto, as subjetividades autodirigidas acontecem na frente dos holofotes, conferindo uma visibilidade expandida da vida ordinária. 
Voltando à noção de memória mediada de Van Dijck (2007), é possível perceber que esse comportamento configura uma narrativa que é reconstruída, o tempo todo, a partir de fragmentos que são compartilhados na rede. Se não há relato sem experiência, tampouco há experiência sem narração. Conforme Latour (2012) explicita, toda ação requer a confecção de um relato sobre si mesma, e quando traçamos conexões sociais estamos compondo relatos. E, segundo Sarlo em “Tempo passado" (2007), a linguagem é que livra a experiência do esquecimento e a transforma no comunicável, ou seja, no "comum". Para a autora, a narração também cria uma nova temporalidade, que se atualiza a partir dos agenciamentos. Assim, "a narração inscreve a experiência numa temporalidade que não é a de seu acontecer (ameaçado desde seu próprio começo pela passagem do tempo e pelo irrepetível), mas a de sua lembrança" (Sarlo, 2007, p. 25).

Uma das peculiaridades do projeto é que ele se apresenta como uma forma de capturar o movimento das cidades, compondo uma história fluida, e assume um 'compromisso memorialístico' com a experiência cotidiana. Ele se apresenta, então, como um grande arquivo que reúne uma miscelânea de vivências e se torna uma ferramenta para a criação e manutenção do "relato" que cada um pretende contar. Esse "arquivo memorialístico digital" se torna uma parte essencial da existência, uma espécie de enciclopédia do humano - e por que não dizer também das coisas? - que abarca vários elementos vindos de lugares e temporalidades distintas. Nesse arquivo virtual, também se fundamenta a construção do sujeito e de seu lugar no mundo. E essa identidade é mutável, volátil, está em constante modificação. É nesse local que se configura a troca, que se perde a autoria, que emerge uma nova forma de sociabilidade.

A construção desses relatos acontece por meio da conversação entre os pares. Para Igarza, em "Nuevas formas de consumo cultural" (2010), a sensação de estar entre amigos gera maior adesão pela sensação de credibilidade. E essas práticas de encadeamento de um relato comum geram um grande impacto no consumo de 
conteúdos e na construção de uma memória cultural. A audiência é consolidada pelo processo de adesão e recomendação, sendo formada pela circulação de sentidos, pelas camadas de mediação. Ser audiência modifica o vínculo fundamental entre os atores sociais, pois aumenta o contato virtual e a sensação de participação. Além disso, ser audiência significa produzir rastros, deixar vestígios da sua experiência.

Assim, a ideia de rastros digitais se opõe a ideia de rastros como vestígio original e verdadeiro, tornando-se uma forma frágil e ambígua de se conceber a experiência. Mas, toda experiência não traz em si a ambiguidade de não se fazer compreensível no instante mesmo em que acontece? E não seria essa a ambiguidade que habita também os rastros digitais? Na visão de Fernanda Bruno em "Rastros digitais" (2012), eles são uma espécie de "quase-objetos" que podem ser mais ou menos visíveis, resistentes, rastreáveis, duradouros ou voluntários. A partir da problematização desse caráter controverso dos rastros digitais, torna-se possível pensar em políticas e poéticas da memória, dando visibilidade às linhas de força que se fazem presentes na sua estruturação e evidenciando as múltiplas vozes e conexões que afetam a experiência.

\section{Entre o político e o poético}

Latour (2012) afirma que levantar uma questão política é investigar a presença de forças até então ocultas, fazendo emergir algo que ainda não tinha sido visto. A política se inscreve como uma forma de experiência problematizante que abarca indícios de uma relação conflituosa na existência do "comum". Isso porque, segundo Rancière, em “O desentendimento" (1996), a política é assunto de sujeitos, de subjetivação, e "caminha a par com a reconfiguração do campo da experiência" (Rancière, 1996, p. 47). Essa subjetivação política "desfaz e recompõe as relações entre os modos de fazer, os modos do ser e os modos de dizer que definem a organização sensível". E isso provoca cenas polêmicas e paradoxais ao convocar "existências que são ao mesmo 
tempo inexistências ou inexistências que são ao mesmo tempo existências" (Rancière, 1996, p. 52).

Para Latour, em "Se falássemos um pouco de política?", "a expressão política deverá sempre confessar que ela é torta, retorcida, esperta, comprometedora, infiel, manipuladora, mutável" (Latour, 2004, p. 15). É justamente nesse jogo, na falta de compromisso com o factual e na abertura para o imaginário, que surge o cruzamento entre o político e o poético. E nesse ato de passagem se encontra a lógica dos coletivos sociotécnicos, as interfaces fluidas, e a já citada questão dos metadados. Uma breve análise desses elementos permite indicar alguns caminhos possíveis na criação de memórias em ambientes programáveis.

O primeiro elemento relaciona-se ao modo como a dinâmica das redes perpassa a construção dos conteúdos produzidos pelos grupos sociais nesses ambientes. Segundo Sarlo, em "O animal político na web" (2011), nos ambientes virtuais, a subjetividade se torna uma parte intrínseca do processo de construção de sentido, reconfigurando as fronteiras entre público e privado. A subjetividade está diretamente ligada ao que Sarlo chamou de "dinâmica do boato", pois, dentro da lógica do compartilhamento, as histórias são reproduzidas sem a certificação da verdade. Nesse caso, o caráter factual não é importante porque o encadeamento de conteúdo "se adapta bem às teorias conspiratórias, que são seu modelo interpretativo predileto" (Sarlo, 2011, p. 9). Dessa forma, "a presença na web não obedece às leis de produção da informação nem da difusão da opinião comuns há dez anos" (Sarlo, 2011, p. 9-10). Essa afirmação suplementa a ideia de que "a rede é o espaço mais poroso que a humanidade inventou até hoje" (Sarlo, 2011, p. 12).

A análise de Sarlo permite, talvez, conjugar dois caminhos que parecem se opor: de um lado, as histórias reproduzidas sem a certificação da verdade; de outro, a subjetividade como parte intrínseca do processo de construção de sentido. A proposta 
de relacionar os dois caminhos baseia-se na ideia de criar lugares imaginários. Em This is Now, o que parece surgir são lugares povoados de registros individuais que habitam um espaço comum e que geram espaços imaginários. Não é exatamente a história das cidades que está sendo contada, pelo menos não do ponto de vista da legitimidade. Esse arquivo virtual é um espaço também de criação, de imaginação. E se ele parece muito distante de uma certificação da verdade, talvez seja o caso de não associar a verdade ao registro da experiência, ou melhor, compreender que o registro da experiência talvez só nos mostre sua própria ruína.

Propomos pensar a ruína como uma marca temporal, como marca da passagem, como memória que se reconstrói a todo o tempo, que não se deixa absorver por um registro estático da sua presença. Os lugares imaginários nos parecem ser, justamente, esses espaços que provocam vários questionamentos, na relação entre o poético e o político: afinal, ecoando Latour (2004), se a política é o que faz emergir aquilo que ainda não tinha sido visto, não é justamente um ato político/poético que se encontra dentro de This is Now? Não seria essa a mistura que borra a oposição entre uma certificação da verdade e a presença intrínseca da subjetividade nos processos de construção do sentido?

No caso do This is Now, não há grupos sociais articulados previamente na produção de imagens. A forma como a plataforma propõe a visualização das imagens é que permite perceber o surgimento de uma memória cultural não ritualizada, produzida de forma descentralizada, sem hierarquia, mas que poderia ser considerada como cultural em função do modo como o projeto agrega as informações dispersas no Instagram. Há aqui, ao mesmo tempo, a memória comunicativa, presente em cada coletivo sociotécnico, e a memória cultural em constante construção, uma vez que o sistema continua a construir novas memórias, de acordo com a entrada das imagens. A interface do projeto se associa à própria imprevisibilidade e ao pluralismo da rede para 
nos provocar a pensar em uma memória que é, simultaneamente, registro e criação de relações entre uma produção coletiva não-hierarquizada. Ao consultar o This is Now, o usuário produz memórias culturais derivadas de uma poética que mescla bancos de dados e programação, que cria arquiteturas de memórias baseadas em meta-dados, ou o que pode ser descrito como "metadata memories".

O segundo elemento-chave se relaciona às interfaces fluidas utilizadas no projeto, e o modo como elas participam da produção de conteúdo. Ao permitir o registro cotidiano "permanente" de fatos, a utilização dos celulares cria uma memória cultural que é atemporal num novo sentido, porque é constantemente atualizável. Os celulares podem intensificar a percepção de que a memória cultural está sempre em constante equilíbrio, entre o acontecimento e a estabilização dos significados. Os metadados produzidos pela câmera se transformam em elementos de conexão com outras imagens e com outras pessoas. O projeto This is Now se torna, por exemplo, um banco de dados com conjuntos de fragmentos visuais de vidas particulares. Mas pode também se tornar grandes conjuntos de memória, dependendo da forma como são organizados, ou como colocam em contato várias pessoas ao redor do mundo. O projeto segue essa lógica de associar um banco de dados extenso e "impessoal" com experiências particulares e momentâneas.

O terceiro elemento que caracterizaria as memórias culturais em rede baseiase na lógica dos metadados. No projeto descrito, o que se vê são memórias que mesclam informações cotidianas com metadados capturados de informações tornadas públicas pelos seus próprios criadores. Assim, a memória cultural aí construída não termina nunca de se fazer, porque os participantes da rede podem sempre alterar os seus metadados, e estão, cotidianamente, postando novas informações na rede, sem necessariamente levarem em conta que elas podem ser agrupadas a partir de parâmetros comuns, como as geotags, por exemplo. Isso torna necessário repensar 
o próprio termo memória cultural como algo que deveria manter certo caráter de imutabilidade física ao longo de um extenso período de tempo.

Os ambientes programáveis, associados a tecnologias móveis de produção e disponibilização de informação, sugerem a necessidade de um olhar mais cuidadoso sobre o modo como já estão sendo construídas as memórias do futuro, e como tais memórias podem ser mais ou menos voláteis, em função da intensidade do uso que delas fizermos. Os projetos analisados permitem perceber como as interações em rede criam, efetivamente, uma nova arquitetura para as memórias. Ou dito de maneira melhor, uma arquitetura com e através das memórias, espaços de memória instáveis, programáveis e cujo modo de existência talvez possa ser descrito em uma frase, que deixamos aqui a título de conclusão temporária: "todo uso provoca uma memória".

\section{REFERÊNCIAS}

ASSMAN, Jan. Collective memory and cultural identity. New German Critique, n. 69, p. 125-133, 1995.

BROCKMEIER, Jens. Remembering and forgetting: narrative as cultural memory. Culture E Psychology, v. 8 , n. 1, p. 15-43, 2002.

BRUNO, Fernanda Glória. Rastros Digitais: o que eles se tornam quando vistos sob a perspectiva da teoria ator-rede? In: XXI Encontro Anual da Compós, Universidade Federal de Juiz de Fora, 12 a 15 de junho de 2012. Disponível em: <http://www.compos.org.br/>. Acesso em: 01 set. 2012.

COUCHOT, Edmond. A tecnologia na arte: da fotografia à realidade virtual. Porto Alegre: Ed. da UFRGS, 2003. DERRIDA, Jacques. Mal de arquivo: uma impressão freudiana. Rio de Janeiro: Delume Dumará, 2001.

FEATHERSTONE, Mike. Archiving cultures. In: British Journal of Sociology, 2000. p. 161-183. Disponível em: $<$ http://chnm.gmu.edu/courses/rr/f01/cw/archiving.pdf >. Acesso em: 01 set. 2012.

HOSKINS, Andrew. The digital distribution of memory, 2009. Disponível em: <http://www.inter-disciplinary. net/wp-content/uploads/2009/03/hoskins-paper.pdf >. Acesso em: 23 jan. 2010.

HUYSSEN, Andreas. Seduzidos pela memória. Arquitetura, monumentos, mídia. Rio de Janeiro: Aeroplano Editora, 2000.

IGARZA, Roberto. Nuevas formas de consumo cultural: por qué las redes sociales están ganando la batalla de las audiências. In: Revista Comunicação, mídia e consumo, São Paulo: ESPM, ano 7, v. 7, n. 20, 2010. 
LATOUR, Bruno. Reagregando o social: uma introdução à Teoria do Ator-Rede. Bahia: EDUFBA, 2012.

. Se falássemos um pouco de política? In: Política e Sociedade - Revista de Sociologia Política, Florianópolis:

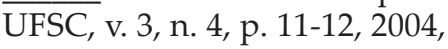

LEROI-GOURHAN, André. O gesto e a palavra. Lisboa: Edições 70, 1990. v. 1.

NEVES, José Pinheiro. O apelo do objeto técnico. Porto: Campos das Letras, 2006.

RANCIÈRE, Jacques. O desentendimento: política e filosofia. São Paulo: Ed. 34, 1996.

SANTAELLA, Lucia; LEMOS, Renata. Redes sociais digitais: a cognição conectiva do Twitter. São Paulo: Paulus, 2010.

SARLO, Beatriz. O animal político na web. In: Serrote - Revista de ensaios, artes visuais, ideias e literatura. São Paulo: Instituto Moreira Salles, n. 7, mar. 2011.

. Tempo passado: cultura da memória e guinada subjetiva. São. Paulo: Companhia das Letras, 2007.

SIBILIA, Paula. O show do eu: a intimidade como espetáculo. Rio de Janeiro: Nova Fronteira, 2008.

VAN DIJCK, José. Mediated memories in the digital age. Stanford: Stanford University Press, 2007.

Recebido em: 18 out 2013

Aceito em: 10 jul. 2014

\section{Endereço dos autores:}

Carlos Henrique Rezende Falci <chfalci@gmail.com> Luciana Andrade Gomes <lucianadrade@gmail.com>

Programa de Pós-Graduação em Arte - UFMG

Escola de Belas Artes - UFMG

Av. Antônio Carlos, 6627 - Pampulha

31270-901 Belo Horizonte, MG, Brasil

Tel.: (31) 3409-5260 - Fax: 3409-5270 